\title{
Maxillofacial Radiology 188
}

SADJ March 2021, Vol. 76 No. 2 p100

\section{CJ Nortjé ${ }^{1}$, J Walters ${ }^{2}$}

The accompanying clinical image (Figure 1) cropped pantomograph (Figure 2) and CT axial bone window slice (Figure 3) depicts a 22-year-old male with a 5-month history of a persistent facial swelling. He reported no pain with nasal obstruction and difficulty breathing as the only symptoms. What would your provisional diagnosis be?
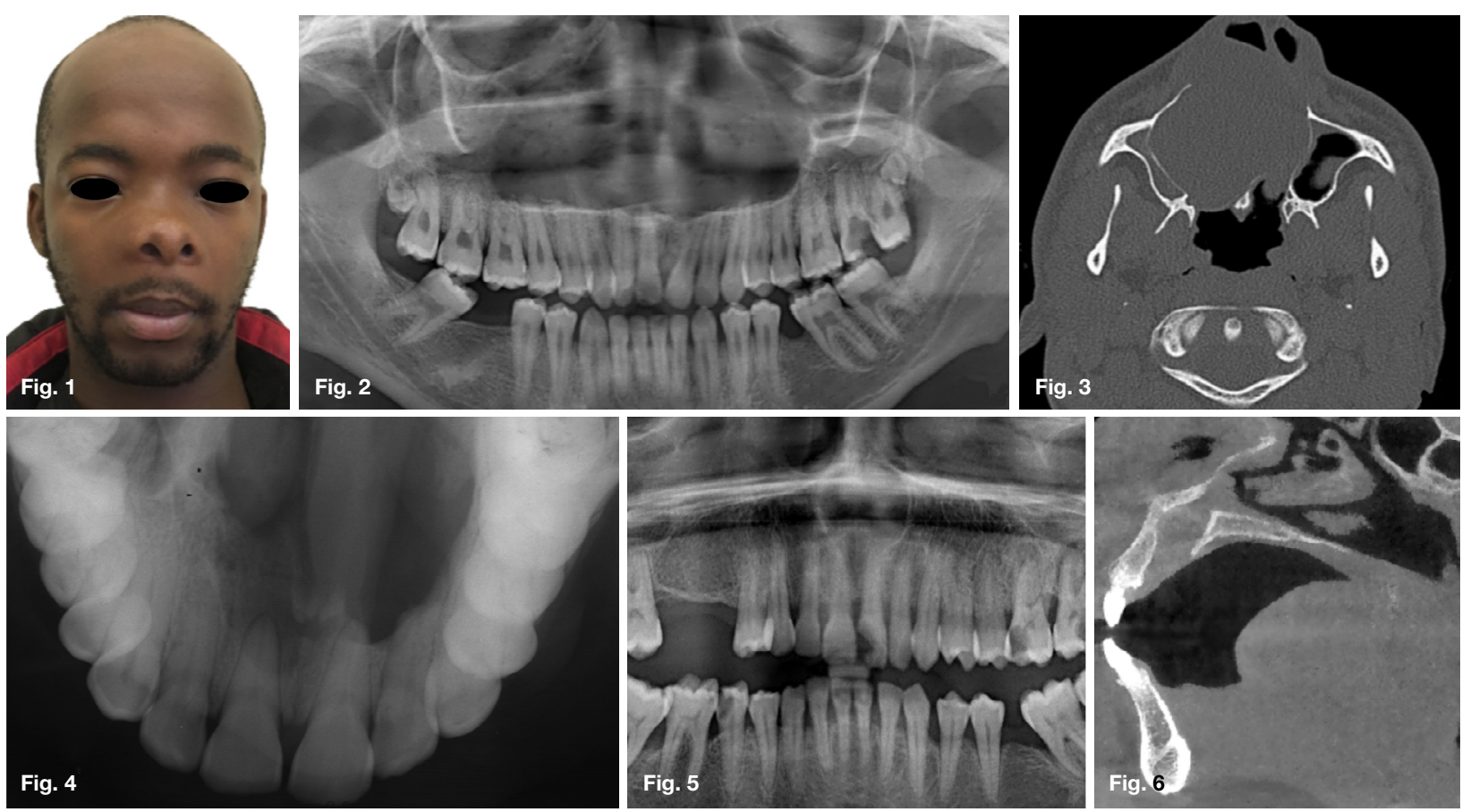

INTERPRETATION

A bulging swelling was observed in the anterior maxilla that resulted in displacement of nasal features and enlargement of the right nostril. Adjacent teeth tested vital and the contents radiodensity measured approximately 22 Hounsfield units $(\mathrm{HU})$ on CT imaging. An occlusal (Figure 4) cropped pantomograph (Figure 5) and sagittal CBCT slice (Figure 6) depict lesions of a similar origin. Aspiration produced a viscous yellow-brownish fluid, and a biopsy of the cystic-like lining was submitted for analysis. Diagnosis of a 'nasopalatine duct (incisive canal) cyst' was made. The most common non-odontogenic cyst and thought to originate from embryonic epithelial residues. When found in the canal, above mentioned synonymous designations would suffice. When within soft tissue at the foramen 'cyst

\section{Author affiliations:}

1. Christoffel J Nortjé: $B C h D, P h D, A B O M R$, DSc. Faculty of Dentistry, University of the Western Cape. ORCID Number: 0000-0002-9717-5514

2. Jaco Walters: BChD PDD (MFR) PGD (OS) MSc (MFR), Department of Oral and Maxillofacial Radiology, Faculty of Dentistry, University of the Western Cape, Tygerberg Oral Health Centre, South Africa.

ORCID Number: 0000-0002-0593-6890

Corresponding author: Jaco Walters

Department of Oral and Maxillofacial Radiology, Faculty of Dentistry, University of the Western Cape, Tygerberg Oral Health Centre, South Africa.

Email: jawalters@uwc.ac.za

Author contributions:

1. Christoffel J Nortjé: Principal author - $50 \%$

2. Jaco Walters: Second author $-50 \%$ of the palatine papilla' would be preferred. Frequency has shown to be $1.4 \%$ in a population where is of identified non-odontogenic cysts, $73.4 \%$ are nasopalatine duct cysts. Predominance is seen between the $3^{\text {rd }}$ and $6^{\text {th }}$ decade with male prevalence at a ratio of 2.5:1. Appearing between the roots of the maxillary central incisors' apical region in the midline of the palate. Radiographic features include a unilocular round or ovoid-shaped homogenous corticated smooth bordered bilateral symmetric cystic-like radiolucency, tooth displacement may be present. Less common features include shape variation, root resorption, asymmetrical bulging, and loss of cortication. Distinguishing from similar appearing lesions or an enlarged incisive foramen may be challenging. Radiographic dimensions of greater than $8 \mathrm{~mm}$ in width, $10 \mathrm{~mm}$ anteroposterior, and pronounced asymmetrical bulging, with a thin cortical outline suggests further investigation. Extraordinary lesions can result in superior posterior extension into the nasal cavity with erosion of adjacent structures including the hard palate and nasal septum. 3D-imaging can be beneficial should conventional views be inconclusive. Treatment consists of surgical enucleation.

\section{References}

1. Langlais RP, Langland OE, Nortjé CJ. Diagnostic Imaging of the Jaws. Williams \& Wilkins. 1995.

2. Shear M, Speight PM. Cysts of the Oral and Maxillofacial Regions ( $4^{\text {th }}$ ed.). Blackwell Munksgaard. 2007. 